\title{
Phosphorylation of CREB and Mechanical Hyperalgesia Is Reversed by Blockade of the cAMP Pathway in a Time-Dependent Manner after Repeated Intramuscular Acid Injections
}

\author{
Marie K. Hoeger-Bement and Kathleen A. Sluka \\ Graduate Program in Physical Therapy and Rehabilitation Science, Neuroscience Graduate Program, Pain Research Program, University of Iowa, Iowa City, \\ Iowa 52242
}

\begin{abstract}
Spinal activation of the cAMP pathway produces mechanical hyperalgesia, sensitizes nociceptive spinal neurons, and phosphorylates the transcription factor CAMP-responsive element binding protein (CREB), which initiates gene transcription. This study examined the role of the CAMP pathway in a model of chronic muscle pain by assessing associated behavioral changes and phosphorylation of CREB. Bilateral mechanical hyperalgesia of the paw was induced by administering two injections of acidic saline, $5 \mathrm{~d}$ apart, into the gastrocnemius muscle of male Sprague Dawley rats. Interestingly, the increases in immunoreactivity for CREB and phosphorylated CREB (p-CREB) in the spinal dorsal horn occur $24 \mathrm{hr}$, but not 1 week, after the second injection of acidic saline compared with $\mathrm{pH} 7.2$ intramuscular injections. Spinal blockade of adenylate cyclase prevents the expected increase in p-CREB that occurs after intramuscular acid injection. The reversal of mechanical hyperalgesia by adenylate cyclase or protein kinase A inhibitors spinally follows a similar pattern with reversal at $24 \mathrm{hr}$, but not 1 week, compared with the vehicle controls. The p-CREB immunoreactivity in the superficial dorsal horn correlates with the mechanical withdrawal threshold such that increases in p-CREB are associated with decreases in threshold. Therefore, activation of the cAMP pathway in the spinal cord phosphorylates CREB and produces mechanical hyperalgesia associated with intramuscular acid injections. The mechanical hyperalgesia and phosphorylation of CREB depend on early activation of the cAMP pathway during the first $24 \mathrm{hr}$ but are independent of the cAMP pathway by 1 week after intramuscular injection of acid.
\end{abstract}

Key words: protein kinase A; adenylate cyclase; muscle; CREB; pain; spinal cord

\section{Introduction}

Chronic pain is an abnormal and nonprotective response. This condition is widespread: an estimated 6 million Americans are affected with fibromyalgia, making it a common pain condition (Bennett, 1995). Chronic pain, including musculoskeletal, is not well understood partially because of a lack of appropriate pain models. Current musculoskeletal pain models typically exhibit short-term hyperalgesia or significant tissue damage, or both (Mense, 1993; Schaible and Grubb, 1993). Our laboratory developed a unique model of chronic muscle hyperalgesia. This model is different from other muscle pain models because there is longlasting bilateral mechanical hyperalgesia without significant tissue damage and is maintained by changes in the CNS (Sluka et al., 2001; Skyba et al., 2002).

Activation of the cAMP pathway in the spinal cord is implicated in pain processing. Mechanical hyperalgesia is produced by spinal activation of the cAMP pathway (Sluka, 1997, 2002; Dolan

Received March 11, 2003; revised April 14, 2003; accepted April 28, 2003.

This study was supported by National Institutes of Health Grants R01 NS 39734, K02 AR 02201, and F31 NS43962. Correspondence should be addressed to Dr. K. A. Sluka, Graduate Program in Physical Therapy and Rehabilitation Science, 1-214 Medical Education Building, University of lowa, lowa City, IA 52242. E-mail: ksluka@blue.weeg.uiowa.edu. Copyright $\odot 2003$ Society for Neuroscience $\quad$ 0270-6474/03/235437-09\$15.00/0 and Nolan, 2001). Spinal activation of adenylate cyclase increases responses of spinothalamic tract neurons to pinch but not brushing, which is prevented by pretreatment with a protein kinase A (PKA) inhibitor (Lin et al., 2002). Mice lacking adenylate cyclases 1 and 8 have no changes in acute pain but have decreases in behavioral responses after administration of formalin or complete Freund's adjuvant (Wei et al., 2002). Additionally, mice that carry a null mutation for the type I regulatory subunit $(\operatorname{Ri} \beta)$ of PKA demonstrate a significant reduction in capsaicin-evoked plasma extravasation and nocifensive behaviors in the second phase of the formalin test (Malmberg et al., 1997a). Blocking of adenylate cyclase or PKA prevents the mechanical hyperalgesia and allodynia produced by intradermal, intramuscular, or intraarticular injection of capsaicin (Sluka and Willis, 1997; Sluka, 2002).

Once cAMP activates PKA, the catalytic subunit of PKA translocates to the nucleus and phosphorylates cAMP response element-binding protein (CREB), a transcription factor, at Ser 133 (Gonzalez and Montminy, 1989). An increase in phosphorylated CREB ( $\mathrm{p}$-CREB) occurs after carrageenan paw inflammation (Messersmith et al., 1998), subcutaneous formalin (Ji and Rupp, 1997; Anderson and Seybold, 2000; Wei et al., 2002), and neuropathic pain (Ma and Quirion, 2001; Miletic et al., 2002). 
Phosphorylated CREB corresponds to the time frame of hyperalgesia in neuropathic (Miletic et al., 2002) and inflammatory pain (Ji and Rupp, 1997). Furthermore, the amount of CREB that is phosphorylated appears to be stimulus dependent. Increasing the volume of formalin injected into the rat hindpaw results in an increase in phosphorylated CREB (Ji and Rupp, 1997).

Earlier research has demonstrated the importance of the cAMP pathway in mechanical hyperalgesia and in phosphorylating the transcription factor CREB. Using a chronic muscle pain model that mimics clinically relevant chronic muscle pain such as fibromyalgia, we tested the hypothesis that inhibition of the cAMP pathway by blocking either adenylate cyclase or PKA will result in a decrease in mechanical hyperalgesia. Furthermore, we hypothesized that $\mathrm{p}$-CREB will increase in the early, but not late, maintenance phase of chronic muscle hyperalgesia.

Portions of these data have been published previously (Hoeger and Sluka, 2001, 2002).

\section{Materials and Methods}

The following experiments were approved by the University of Iowa's Animal Care and Use Committee and followed the policies issued by the National Institutes of Health and the International Association for the Study of Pain on the use of laboratory animals. Male Sprague Dawley rats were used in this study (250-350 gm; Harlan, St. Louis, MO; $n=147)$.

Chronic muscle hyperalgesia model. Two injections of $\mathrm{pH} 4.0$ sterile saline ( $100 \mu \mathrm{l}$ for each injection) were administered $5 \mathrm{~d}$ apart into the left gastrocnemius while the animals were anesthetized with vaporized halothane $(2-4 \%)$. This model produces long-lasting bilateral mechanical hyperalgesia without significant muscle tissue damage or motor deficits (Sluka et al., 2001). In some animals, two intramuscular injections of $\mathrm{pH}$ $7.2(100 \mu \mathrm{l})$ sterile saline were used for controls.

Intrathecal injections. An intrathecal catheter was used to administer drugs to the lumbar spinal cord to inhibit the cAMP pathway (Sakura et al., 1996; Storkson et al., 1996; Pogatski et al., 2000). Rats were anesthetized with vaporized halothane $(2-4 \%)$. A vertical incision was made in the skin at the L5-L6 vertebral level. A $10 \mathrm{~cm} 32$ ga polyurethane catheter (Recathco, Allison Park, PA) was placed between the L5 and L6 vertebrae and advanced intrathecally to the L5/L6 level. Movement of the tail or hindlimb verified placement. Next, an $8 \mathrm{~cm}$ polyethylene 10 catheter was fixed to the remaining portion of the 32 ga catheter and exited through the skin. Rats were allowed to recover 5-7 d before the first injection of $\mathrm{pH} 4.0$ saline, which initiated the chronic muscle hyperalgesia. At the end of the experiments, the catheter placement was verified by injecting lidocaine and methylene blue dye. The catheter was considered appropriately placed if there was (1) loss of pinprick and motor paralysis to lidocaine and (2) dye covering L4-L6 spinal levels.

Behavioral testing. Mechanical withdrawal threshold was used as a measure of hyperalgesia to study the effects of spinal blockade of the cAMP pathway. Von Frey filaments (North Coast Medical, Morgan Hill, CA; $1-350 \mathrm{mN}$ bending force) were used to measure the mechanical withdrawal threshold. We measured hyperalgesia outside the intramuscular acid injection in the skin. This is interpreted as secondary hyperalgesia and thought to reflect changes in the CNS (Willis and Coggeshall, 1991). Rats were placed in clear plastic cubicles on an elevated wire mesh and allowed to acclimate for $20-30 \mathrm{~min}$. The filaments were applied to the paw in ascending order starting with the lowest bending force. Two trials per filament were performed. The paw had to lift for two sequential filaments for the force to be recorded. Behavioral tests were performed in a blinded manner in some animals. This type of behavior testing has been demonstrated to be a reliable measurement of mechanical withdrawal threshold (Gopalkrishnan and Sluka, 2001).

Drugs. Two drugs were used to inhibit the cAMP pathway at separate locations along the pathway. SQ 22536 (Biomol, Plymouth Meeting, PA), used to block adenylate cyclase, was dissolved in $16 \%$ DMSO. The following doses were tested: $0.064,0.2$, and $0.715 \mu \mathrm{mol}$. DMSO (16\%) was used as its control during behavioral testing. Myristoylated protein kinase inhibitor (PKI) (14-22) amide (Biomol) dissolved in saline and deionized water was used to inhibit PKA. This drug was tested at 2, 20, 60, and $100 \mathrm{nmol}$ doses. Saline was used as its control. We chose to use these drugs because of their specificity. For example, PKI peptides are extremely specific and potent inhibitors of the PKA catalytic subunit (Walsh and Glass, 1991). Specifically, myristoylated PKI (14-22) amide is an effective inhibitor of PKA (Harris et al., 1997) and blocks hyperalgesia produced by spinal administration of 8-bromo-cAMP (Sluka, 2002).

Immunohistochemical labeling. Standard immunohistochemical labeling was used to assess the location of cells in which CREB had been phosphorylated after induction of hyperalgesia (Sluka and Westlund, 1993; Messersmith et al., 1998). Rats were anesthetized by sodium pentobarbital (100 mg/kg, i.p.) and perfused through the left ventricle with $100 \mathrm{ml}$ of heparinized saline followed by 11 of $4 \%$ paraformaldehyde in $0.1 \mathrm{~m}$ phosphate buffer (PB), $\mathrm{pH} 7.4,4^{\circ} \mathrm{C}$. Segments $\mathrm{L} 5$ and $\mathrm{T} 10$ of the spinal cord were removed and placed in 30\% sucrose solution overnight.

Tissue was cut on a cryostat at $40 \mu \mathrm{m}$ thickness and placed in PB. These sections underwent a step-wise procedure that included $0.5 \% \mathrm{H}_{2} \mathrm{O}_{2}, 1 \%$ $\mathrm{Na}$-borohydride, solution A (avidin), solution B (biotin), and 3\% normal goat serum (NGS). Between each step, tissue was rinsed in PBS. Next, sections were incubated overnight in primary antibody in $1 \%$ NGS/PBS containing $0.75 \%$ Triton X-100 at room temperature as follows: antiCREB $(1: 10,000)$ (Upstate Biotechnology, Lake Placid, NY) and anti-pCREB (1:5000) (Upstate Biotechnology). The anti-p-CREB recognizes phosphorylation at the PKA site, Ser 133 (Gonzalez and Montminy, 1989). Preliminary dilution series for CREB and p-CREB determined appropriate concentrations for the $1^{\circ}$ antibody.

Preabsorption controls for anti-CREB and anti-p-CREB were performed, indicating their specificity to the protein using the exact immunohistochemical protocol except for the addition of the immunizing peptide. Specifically, CREB immunizing peptide $(16.7 \mu \mathrm{g} / 1 \mathrm{ml})$ (Upstate Biotechnology) was added to CREB primary antibody, and p-CREB immunizing peptide $(16.7 \mu \mathrm{g} / 1 \mathrm{ml}$ ) (Upstate Biotechnology) was added to p-CREB primary antibody. After $30 \mathrm{~min}$ at room temperature, the appropriate solution was added to tissue sections. Simultaneously, another sample of tissue was immunohistochemically stained with antibodies to CREB and $\mathrm{p}$-CREB to ensure that changes were caused by the addition of the immunizing peptide. No staining was observed in tissue sections incubated with the immunizing peptide (see Fig. $3 C, F$ ).

Sections were washed in PBS and 3\% NGS followed by incubation for $1 \mathrm{hr}$ in the secondary antibody biotinylated-goat anti-rabbit IgG (Vector Laboratories, Burlingame, CA; 1:1000). After they were washed in PBS and $3 \%$ NGS, sections were incubated in avidin horseradish peroxidase ( $1 \%$ NGS with $0.75 \%$ Triton X-100; $1: 1000$ ) for $1 \mathrm{hr}$. This was followed by $6 \mathrm{~min}$ in $0.05 \%$ diaminobenzidine (DAB) and $0.01 \% \mathrm{H}_{2} \mathrm{O}_{2}$. Sections were washed and mounted on slides, allowed to dry for $24-48 \mathrm{hr}$ before cleaning in ethanol/water and propar, and coverslipped.

To minimize differences in staining between animals, each group was run simultaneously, i.e., pH 4.0 and pH 7.2 or saline and SQ 22536. Furthermore, between groups the exact staining protocol was used, including incubation in primary and secondary antibodies and DAB.

Density readings. Three spinal cord sections (L5) were randomly chosen from each rat. All density readings were performed with the experimenter blinded to group except for initial preliminary data. Images were generated using an Olympus BX-51 microscope. The superficial laminas (I-II) and intermediate and deep dorsal horn (III-VI) were outlined, and the number of pixels occupied by immunoreactive cells was measured using Image J 1.24 software (NIH) (Le Guen et al., 1998; Martin et al., 1999; Wei et al., 2002). Specifically, each tissue section was first converted to eight-bit gray scale, and then each tissue section was calibrated independently using the "uncalibrated OD" function with pixel values ranging from 0 to 255 . The density values represent pixels per area. A background reading taken from the white matter of the dorsal column was subtracted from the density reading taken from the gray matter of the same tissue section. This controls for differences in nonspecific staining as a result of the $\mathrm{DAB}$ reaction.

Motor testing. The PKA inhibitor produced a significant motor deficit in one rat during the behavioral testing protocol. Therefore, the following experimental drugs were tested for motor effects: $100 \mathrm{nmol}$ PKI $(n=$ 

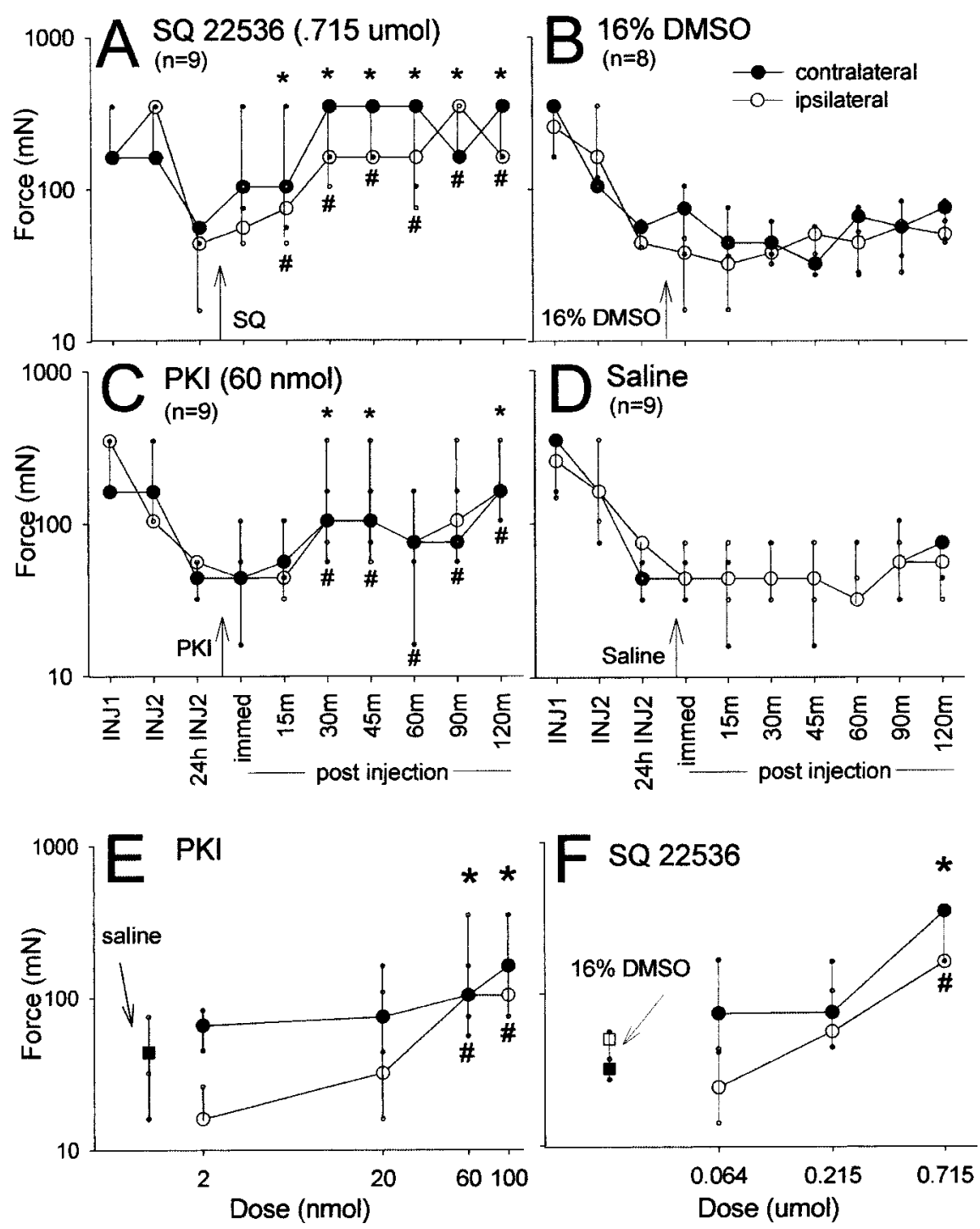

Figure 1. Line graphs showing the effects of the inhibitors of the CAMP pathway on the median mechanical withdrawal threshold $24 \mathrm{hr}$ after the second intramuscular acid injection. $A, B$, Intrathecal administration of SQ22536 (0.7 $\mu \mathrm{mol})$ increases mechanical withdrawal threshold bilaterally compared with the $16 \%$ DMSO control 15 min after drug administration and remains increased for the next $2 \mathrm{hr} . C, D$, Intrathecal administration of PKI $(60 \mathrm{nmol})$ increases mechanical withdrawal threshold bilaterally compared with the intrathecal saline control. $E_{1} F_{1}$ A dose-dependent increase in mechanical withdrawal threshold is observed 45 min after spinal blockade of adenylate cyclase (SQ22536) or protein kinase A (PKI). INJ1, Before first intramuscular injection of pH 4.0 saline; INJ2, before second intramuscular injection of pH 4.0 saline; $24 \mathrm{hr} \mathrm{INJ2,} 24 \mathrm{hr}$ after second intramuscular injection of pH 4.0 saline. Data are presented as the median with the 25 th and 75 th percentiles. *Contralaterally and ${ }^{\#}$ ipsilaterally significantly different from vehicle control; $p \leq 0.05$

9), $60 \mathrm{nmol}$ PKI $(n=5)$, and $0.715 \mu \mathrm{mol} \mathrm{SQ22536}(n=4)$ against a saline control $(n=4)$ using the Rota-Rod treadmill test and placing reflex. The rats were trained on the treadmill (Ugo Basile Rota-Rod, Stoelting, Wood Dale, IL) for $2 \mathrm{~d}$ before the testing, which included three sessions of three intervals given daily with an intersession interval $>2 \mathrm{hr}$ and an intertrial interval $>5 \mathrm{~min}$. Motor involvement was tested after intrathecal drug administration in $15 \mathrm{~min}$ intervals for the first hour followed by $30 \mathrm{~min}$ intervals for the second hour.

Experimental design. The following drugs were used to determine the effects of inhibiting the cAMP pathway on chronic muscle hyperalgesia: (1) adenylate cyclase inhibitor, SQ 22536, and (2) PKA inhibitor, myristoylated PKI (14-22) amide. The adenylate cyclase inhibitor was dissolved in $16 \%$ DMSO, and behavioral testing was performed at the doses of $0.064,0.2$, and $0.715 \mu \mathrm{mol}$. The PKA inhibitor was dissolved in saline and deionized water, and behavioral testing was performed at the doses of 2, 20, 60, and $100 \mathrm{nmol}$. We demonstrated previously that $60 \mathrm{nmol}$ of the PKA inhibitor (PKI) reverses the mechanical hyperalgesia produced by spinal administration of 8-bromo-cAMP (Sluka, 2002). The drug dose quantities were determined by preliminary data, previously published data (Sluka 1997), and the dissociation constant for binding of inhibitor to enzyme (reported by the manufacturer, Biomol).

In the first series of experiments, intrathecal catheters were placed in male Sprague Dawley rats. After 5-7 d, the chronic muscle hyperalgesia model was induced, which involves administering two intramuscular injections of $\mathrm{pH} 4.0$ saline $5 \mathrm{~d}$ apart. Twenty-four hours after the second intramuscular injection of $\mathrm{pH} 4.0$ saline, the following drugs were administered intrathecally: (1) adenylate cyclase inhibitor, SQ $22536(0.715 \mu \mathrm{l}$ dose, $n=9$; $0.215 \mu \mathrm{l}$ dose, $n=$ 5; $0.064 \mu$ l dose, $n=4)$, (2) PKA inhibitor, myristoylated PKI $(14-22)$ amide $(100 \mathrm{nmol}$, $n=9 ; 60 \mathrm{nmol}, n=9 ; 20 \mathrm{nmol}, n=7 ; 2 \mathrm{nmol}$, $n=4)$, (3) saline control, pH $7.2(n=9)$, or $(4)$ $16 \%$ DMSO in saline control $(n=8)$. Similarly, 1 week after the second injection, the following drugs were tested: (1) adenylate cyclase inhibitor, SQ 22536 (0.715 $\mu$ l dose; $n=6)$, (2) PKA inhibitor, myristoylated PKI (14-22) amide (60 $\mathrm{nmol} ; n=8)$, (3) saline control, pH $7.2(n=6)$, (4) $16 \%$ DMSO in saline control $(n=6)$. Mechanical withdrawal threshold was measured (1) before each intramuscular injection of $\mathrm{pH}$ 4.0 saline, (2) $24 \mathrm{hr}$ or 1 week after the second intramuscular injection of $\mathrm{pH} 4.0$ saline (before drug administration), and (3) after drug administration in $15 \mathrm{~min}$ intervals for the first hour followed by $30 \mathrm{~min}$ intervals for the second hour.

In the second series of experiments, two injections of $\mathrm{pH} 4.0$ or 7.2 were given into the left gastrocnemius $5 \mathrm{~d}$ apart. Twenty-four hours and 1 week after the second injection, immunohistochemistry was performed for CREB and p-CREB. Spinal cord sections from animals injected intramuscularly with $\mathrm{pH} 4.0$ or 7.2 were immunostained simultaneously.

In another group of animals, $24 \mathrm{hr}$ after the second injection into the left gastrocnemius, the adenylate cyclase inhibitor or vehicle control was injected intrathecally. Once the decreased mechanical withdrawal threshold reached its maximum reversal, $\sim 60 \mathrm{~min}$ after intrathecal injection, rats were perfused and immunohistochemistry was performed to identify CREB and p-CREB.

Statistical analysis. The results from the behavior testing using the von Frey filaments were not normally distributed; therefore, a nonparametric Kruskal-Wallis ANOVA was used. If differences were present, a post hoc Wilcoxon signed ranks test was used. Statistical analysis for the density readings was done using a one-way ANOVA. A Pearson productmoment coefficient of correlation was used to determine the relationship between mechanical withdrawal threshold and the density of the p-CREB immunoreactivity $24 \mathrm{hr}$ after the second injection of acidic saline. Statistical significance was determined by $p<0.05$.

\section{Results}

Behavioral effects of repeated intramuscular acid injections The animals demonstrated the same pattern of hyperalgesia, as reported previously (Sluka et al., 2001). Specifically, there was a bilateral decrease in mechanical withdrawal threshold $24 \mathrm{hr}$ and 1 
week after the second intramuscular injection of acidic saline. The mechanical withdrawal thresholds did not change significantly after spinal administration of saline (PKI control) or 16\% DMSO (SQ 22536 control).

\section{Inhibition of adenylate cyclase}

The adenylate cyclase inhibitor, SQ 22536, was injected intrathecally $24 \mathrm{hr}$ or 1 week after the second intramuscular injection of $\mathrm{pH} 4.0$ saline to assess the role of the cAMP pathway in the early and late maintenance phases of chronic muscle hyperalgesia. The highest dose of SQ 22536 administered $24 \mathrm{hr}$ after the second intramuscular injection of $\mathrm{pH} 4.0$ saline increased the mechanical withdrawal threshold bilaterally (Fig. $1 A$ ). Significant increases from 16\% DMSO control occurred $15 \min (p=0.008), 30 \mathrm{~min}$ $(p=0.0001), 45 \mathrm{~min}(p=0.0001), 60 \mathrm{~min}$ $(p=0.002), 90 \mathrm{~min}(p=0.0001)$, and 120 $\min (p=0.001)$ ipsilaterally, and $15 \mathrm{~min}$ $(p=0.027), 30 \min (p=0.006), 45$ $\min (p=0.008), 60 \min (p=0.006), 90$ $\min (p=0.001)$, and $120 \min (p=0.008)$ contralaterally. The effects of SQ 22536 are dose dependent 45 min after drug administration, with the highest dose showing almost complete reversal of hyperalgesia contralaterally and ipsilaterally (Fig. $1 E$ ).

The mechanical withdrawal threshold re-

mained unchanged if the SQ 22536 was administered 1 week after the second intramuscular injection of $\mathrm{pH} 4.0$ saline (Fig. $2 \mathrm{~A}$ ).

\section{Inhibition of protein kinase A}

To further demonstrate the role of the cAMP pathway in chronic muscle hyperalgesia, a PKA inhibitor was injected intrathecally $24 \mathrm{hr}$ and 1 week after the second intramuscular injection of $\mathrm{pH}$ 4.0 saline. The highest dose of PKI (100 nmol) administered $24 \mathrm{hr}$ after the second intramuscular injection of $\mathrm{pH} 4.0$ saline increased the mechanical withdrawal threshold bilaterally. Significant increases from intrathecally administered saline control occurred 45 $\min (p=0.031), 60 \min (p=0.0001), 90 \min (p=0.0001)$, and $120 \mathrm{~min}(p=0.014)$ ipsilaterally, and $30 \mathrm{~min}(p=0.014), 45 \mathrm{~min}$ $(p=0.006), 90 \mathrm{~min}(p=0.05)$, and $120 \mathrm{~min}(p=0.003)$ contralaterally. The second highest dose of PKI (60 nmol) administered $24 \mathrm{hr}$ after the second intramuscular injection of $\mathrm{pH} 4.0$ saline also increased the mechanical withdrawal threshold bilaterally (Fig. $1 C$ ). Significant increases from saline control occurred $30 \min (p=0.024), 45 \min (p=0.05), 60 \min (p=$ $0.008), 90 \mathrm{~min}(p=0.04)$, and $120 \mathrm{~min}(p=0.002)$ ipsilaterally, and $30 \mathrm{~min}(p=0.04), 45 \mathrm{~min}(p=0.014)$, and $120 \mathrm{~min}(p=$ $0.006)$ contralaterally. The effects of PKI are dose dependent, with the two highest doses showing reversal of hyperalgesia ipsilaterally and contralaterally (Fig. $1 F$ ). The mechanical withdrawal threshold remained unchanged if the PKI was administered 1 week after the second intramuscular injection of $\mathrm{pH} 4.0$ saline (Fig. 2C).

\section{Motor involvement}

The potential effects that the drugs may have on motor impairment were tested for both the SQ 22536 (0.7 mol dose) and PKI (60 and $100 \mathrm{nmol}$ doses) using the Rota-Rod treadmill test. Both drugs were injected intrathecally and monitored for motor function for the same $2 \mathrm{hr}$ duration as the experimental protocol. Rats injected with SQ22536 had no motor involvement compared with the rats injected intrathecally with saline; all of the rats were able to stay on the treadmill for the maximum $150 \mathrm{sec}$. After intrathecal injection of PKI, three of the nine rats given the 100 nmol dose were excluded from the treadmill testing because of paralysis. Rats injected with PKI that were not paralyzed $(n=6)$ showed no significant difference when compared with the saline control. In previous behavioral experiments, this exclusive procedure was also used. For instance, if any of the rats appeared to have severe motor involvement after intrathecal administration of the drug, the rats were automatically excluded from behavioral testing.

\section{CREB}

There was a bilateral increase in CREB and p-CREB immunoreactivity in $\mathrm{L} 524 \mathrm{hr}$ after intramuscular injection of $\mathrm{pH} 4.0$ saline when compared with pH 7.2 (Fig. 3). CREB immunoreactivity increased ipsilaterally in the superficial $(p=0.038)$ and deep $(p=0.039)$ dorsal horn and contralaterally in the superficial $(p=0.03)$ and deep $(p=0.029)$ dorsal horn when compared with rats receiving pH 7.2 intramuscular injections (Fig. $4 A, B$ ). $\mathrm{p}$-CREB significantly increases ipsilaterally in the superficial $(p=$ $0.04)$ and deep $(p=0.034)$ dorsal horn and contralaterally in the superficial dorsal horn $(p=0.012)$ when compared with rats receiving $\mathrm{pH} 7.2$ intramuscular injections (Fig. $4 A, B$ ). CREB and p-CREB immunoreactivity 1 week after the second intramuscular acid injection were not significantly different from the $\mathrm{pH} 7.2$ controls (Fig. 4C,D).

These changes in immunoreactivity for $\mathrm{CREB}$ and $\mathrm{p}-\mathrm{CREB}$ did not occur in tissue sections from T10. CREB immunoreactiv- 


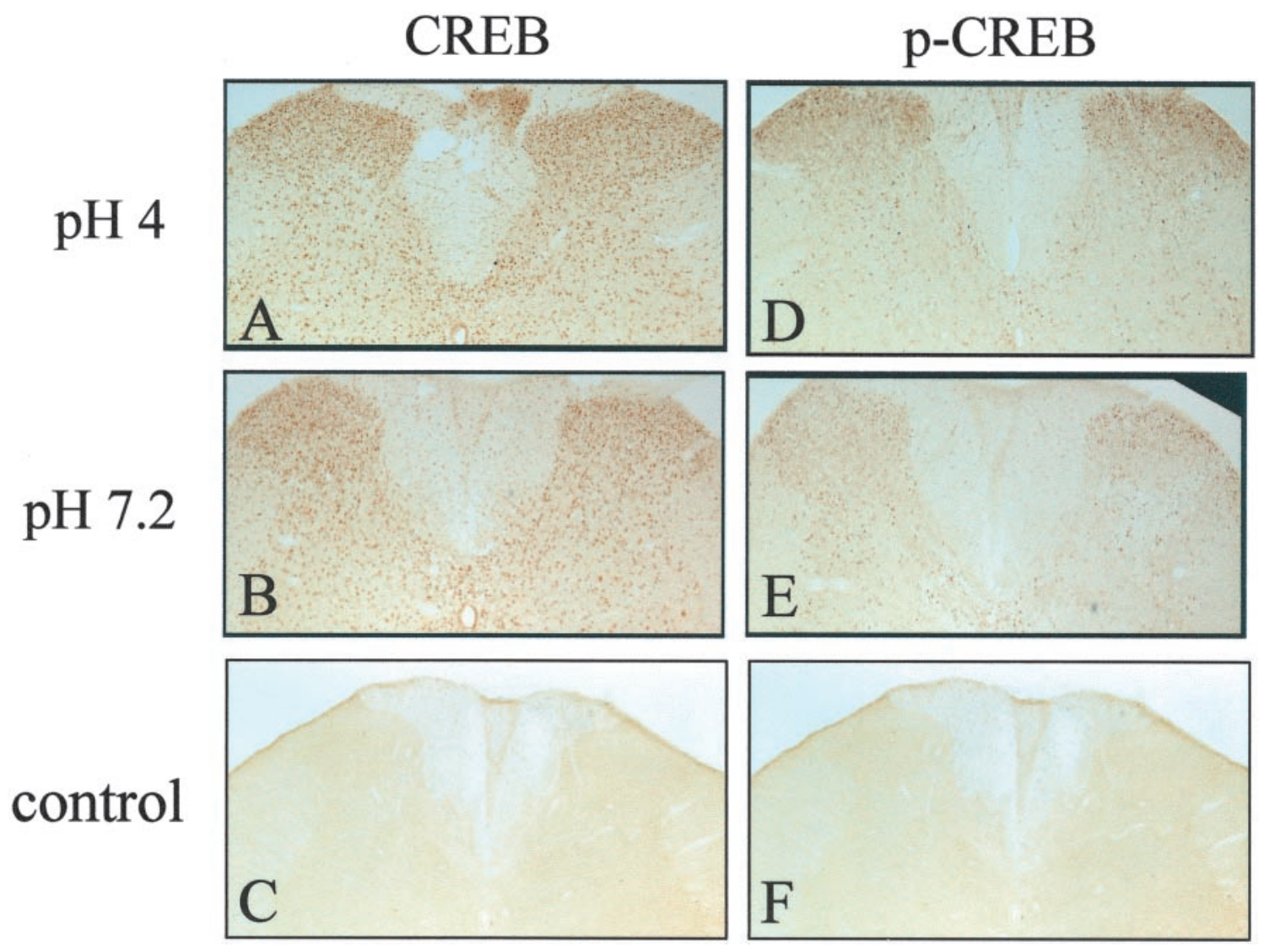

Figure 3. Immunohistochemistry of CREB and p-CREB $24 \mathrm{hr}$ after the second intramuscular injection of pH 4.0, pH 7.2 control, or the preabsorption control. Both CREB and p-CREB densities increase $24 \mathrm{hr}$ after the second intramuscular injection of pH $4.0(A, D)$ compared with the animals that received pH 7.2 saline intramuscular injections $(B, E)$. No staining was observed in tissue sections incubated with the immunizing peptide $(C, F)$.

ity in rats receiving $\mathrm{pH} 4.0$ intramuscular injections did not significantly differ in the ipsilateral superficial $(p=0.41)$ and deep $(p=0.29)$ dorsal horn and contralaterally in the superficial $(p=$ $0.37)$ and deep $(p=0.38)$ dorsal horn when compared with rats receiving pH 7.2 intramuscular injections. p-CREB immunoreactivity in rats receiving $\mathrm{pH} 4.0$ intramuscular injections did not differ significantly in the ipsilateral superficial $(p=0.47)$ and deep $(p=0.43)$ dorsal horn, and contralaterally in the superficial $(p=0.31)$ and deep $(p=0.38)$ dorsal horn when compared with rats receiving $\mathrm{pH} 7.2$ intramuscular injections.

To test whether the increase in $\mathrm{p}$-CREB is mediated by activation of the cAMP pathway, we administered SQ 22536 intrathecally and measured CREB and p-CREB. Spinal administration of SQ 22536 significantly prevented the increase in p-CREB contralaterally in the superficial $(p=0.016)$ and deep $(p=0.048)$ dorsal horn and ipsilaterally in the superficial dorsal horn $(p=$ 0.046) compared with the intrathecal saline control (Fig. 5). Spinal application of SQ 22536 had no effect on CREB (Fig. 5). Thus, it appears that the increase in $\mathrm{p}$-CREB is mediated by activation of the cAMP pathway.

To test for the relationship between $\mathrm{p}$-CREB and mechanical hyperalgesia, the density of staining was tested for correlation with the mechanical withdrawal thresholds. The density of p-CREB immunoreactivity in the superficial dorsal horn $24 \mathrm{hr}$ after the second intramuscular injection of $\mathrm{pH} 4.0$ or 7.2 or after the administration of SQ 22536 or saline is significantly correlated to the mechanical withdrawal threshold on the ipsilateral and contralateral paws (Fig. 6). There was no correlation between the mechanical withdrawal threshold with density readings from the deep dorsal horn. Thus, a decrease in mechanical withdrawal threshold, indicating an increase in mechanical hyperalgesia, is associated with an increase in p-CREB immunoreactivity in the superficial dorsal horn.

\section{Discussion}

This study shows a time-dependent increase in CREB and the phosphorylation of CREB with significant increases $24 \mathrm{hr}$, but not 1 week, after the second intramuscular acid injection. The increase in p-CREB depends on activation of the cAMP pathway because blockade of adenylate cyclase or PKA prevents this increase at $24 \mathrm{hr}$. Changes in p-CREB parallel the cAMP-mediated mechanical hyperalgesia. Furthermore, the staining density for p-CREB in the superficial dorsal horn correlates with the mechanical withdrawal threshold $24 \mathrm{hr}$ after the second intramuscular injection, indicating that behavioral changes at $24 \mathrm{hr}$ are associated with increases in p-CREB. A number of intracellular messengers can phosphorylate CREB at Ser 133, i.e., calcium calmodulin kinase IV, mitogen-activated kinase, extracellular regulated kinase, and PKA (Lonze and Ginty, 2002). This study demonstrates that increases in p-CREB after repeated intramuscular acid injections are reversed by blockade of the cAMP pathway. Thus, these data suggest that phosphorylation of CREB in muscle-induced hyperalgesia is mediated by activation of the cAMP pathway and is time dependent.

\section{Activation of the CAMP pathway and CREB}

CREB is a nuclear protein that mediates the effects of the activation of the cAMP pathway in the transcriptional regulation of a 
large number of peptides and proteins. Specifically, CREB is a transcription factor that binds to the cAMP response element (CRE) promoter site (Shaywitz and Greenberg, 1999). Two types of CREB that have opposing actions may bind to the CRE promoter site. CREB-1 represses gene transcription and CREB-2 activates gene transcription, but only when it is phosphorylated (Bear et al., 2001).

The current study shows that activation of the cAMP pathway phosphorylates CREB, which is required for CRE-mediated transcription, suggesting that an increase in gene transcription may occur in chronic muscle pain. These data agree with previous studies showing an increase in p-CREB in various animal models of pain (Ji and Rupp, 1997; Messersmith et al., 1998; Anderson and Seybold, 2000; Ji et al., 2000; Ma and Quirion, 2001; Miletic et al., 2002; Wei et al., 2002). In both neuropathic and inflammatory pain, the phosphorylation of CREB parallels hyperalgesia (Ji and Rupp, 1997; Miletic et al., 2002). In contrast, our study shows that the increases in $\mathrm{p}$-CREB occur in a time-dependent manner, are mediated by activation of the cAMP pathway, and that the increases in the superficial dorsal horn correlate with the mechanical withdrawal threshold. Thus, the increases in p-CREB after muscle-induced hyperalgesia appear to contribute to the CAMP-

dependent phase of hyperalgesia associated with stimulation of the muscle.

In the current study there was not an area-dependent increase in CREB or p-CREB immunoreactivity as observed after electrical stimulation of the sciatic nerve (White and Helme, 1985; Klein et al., 1990). The changes in CREB and p-CREB are difficult to explain on the basis of activation solely by muscle nociceptors. Types III and IV muscle nociceptors project predominantly to laminas I and V without projections to lamina II (for review, see Mense, 1993; Mense and Prabhakar, 1986). Similarly, changes in substance $\mathrm{P}$ and calcitonin gene-related peptide after knee joint inflammation occur throughout laminas I and II (Sluka et al., 1992; Sluka and Westlund, 1993), although joint afferents terminate primarily in laminas I and V (Craig et al., 1988). One speculation is that increases in CREB and p-CREB are mediated by activation of descending facilitatory pathways secondary to activation of muscle nociceptors (Urban et al., 1999; Porreca et al., 2002). Secondary hyperalgesia involves descending facilitation mediated by supraspinal sites, including the rostral ventral medulla and the anterior cingulate cortex (Urban et al., 1999; Calejesan et al., 2000; Porreca et al., 2002; Wei et al., 2002). Activation of supraspinal sites may also explain the bilateral changes in CREB, $\mathrm{p}-\mathrm{CREB}$, and mechanical hyperalgesia.

The phosphorylation of CREB may contribute to the longlasting hyperalgesia observed in this model by allowing CREB to bind the CRE promoter. The CRE promoter is found in a number of "pain genes," including c-fos (Sassone-Corsi et al., 1988), somatostatin (Gonzales and Montminy, 1989), and neurokinin 1 receptor (Hershey et al., 1991), that are modulated after tissue injury. Furthermore, p-CREB increases in neurokinin-1 receptor
$24 \mathrm{~h}$

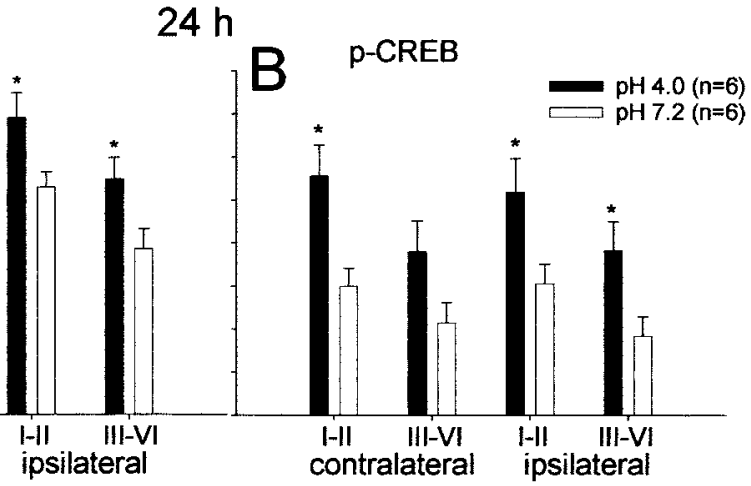

1 wk

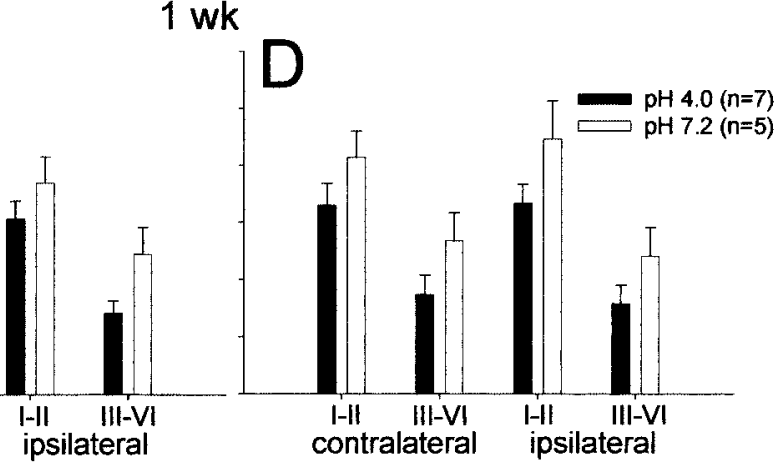
contralateral ipsilateral

Figure 4. Density of CREB and $\mathrm{p}$-CREB immunoreactivity $24 \mathrm{hr}$ and 1 week after the second intramuscular injection of $\mathrm{pH} 4.0$ or

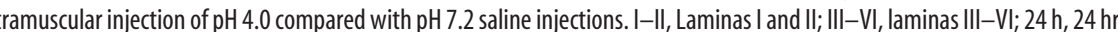
$1 \mathrm{wk}, 1$ week. Data are presented as the average with the SEM. ${ }^{*} p$, significantly different from the $\mathrm{pH} 7.2$ control group; $p<0.05$.

immunoreactive neurons in the spinal cord after formalin injection (Anderson and Seybold, 2000). There may be other CRE promoter sites downstream in which consequences of $\mathrm{p}$-CREB are not identified.

The increase in CREB could represent an upregulation attributable to new synthesis or decreased degradation. Increases in CREB protein, which occur in other systems, would result in a greater pool of protein for phosphorylation. For example, CREB mRNA and CREB immunoreactivity increase in the rat hippocampus after chronic administration of antidepressants as well as phosphodiesterase inhibitors (Nibuya et al., 1996). Therefore, this increase in CREB parallels what is seen in other systems that are mediated by the cAMP pathway.

Activation of the cAMP pathway and mechanical hyperalgesia Activation of adenylate cyclase in neurons can occur through neurotransmitter-receptor interactions or increases in calcium (Xia and Storm, 1997). Adenylate cyclase activation converts ATP to cAMP, which then activates PKA. PKA is involved in neuroplasticity through phosphorylation of various substrates, including ion channels, neurotransmitter receptors, and transcription factors (Gonzalez and Montminy, 1989; Blackstone et al., 1995; Hell et al., 1995). The PKA site on the NR1 subunit of the NMDA receptor is phosphorylated after intradermal capsaicin injection (Zou et al., 2000). The current study provides evidence that PKA can also phosphorylate the transcription factor CREB in an animal model of muscle-induced hyperalgesia.

We propose that activation of the cAMP pathway is involved in a time-dependent manner in the early phase of maintenance but not the later phase or the induction of hyperalgesia. Pretreatment with either an adenylate cyclase or PKA inhibitor has no 


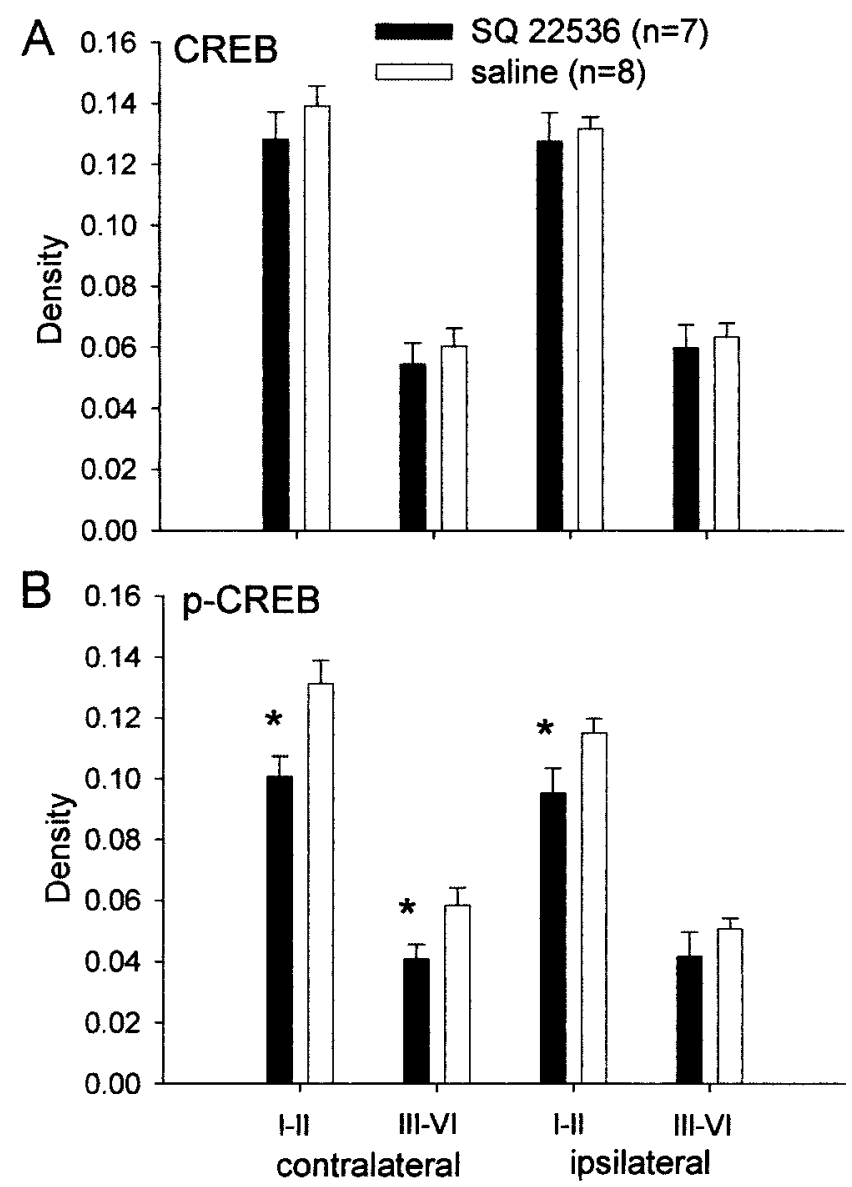

Figure 5. Density of CREB and $p-C R E B$ immunoreactivity after intrathecal treatment with the adenylate cyclase inhibitor, SQ 22536, or saline. A, CREB remains unchanged after spinal inhibition of adenylate cyclase with SQ22536. $B$, The increase in p-CREB is prevented after spinal inhibition of adenylate cyclase with SQ22536 compared with the intrathecal saline control. I-II, Laminas I and II; III-VI, laminas III-VI. Data are presented as the average with the SEM. * Significantly different from saline control; $p \leq 0.05$.

effect on the hyperalgesia produced by intradermal injection of capsaicin (Sluka, 1997). Treatment with an adenylate cyclase or PKA inhibitor $1 \mathrm{hr}$ after intradermal capsaicin or $24 \mathrm{hr}$ after intra-articular or intramuscular injection of capsaicin reverses secondary mechanical hyperalgesia (Sluka, 1997, 2002). In contrast, treatment 1 week after intra-articular or intramuscular injection of capsaicin has no effect on mechanical hyperalgesia (Sluka, 2002). Our results parallel these previous behavioral studies with a reduction in hyperalgesia at $24 \mathrm{hr}$, but not 1 week, after repeated intramuscular acid injection. We further these results by showing that phosphorylation of CREB occurs in the same timedependent manner and that the changes in p-CREB at $24 \mathrm{hr}$ correlate with the mechanical withdrawal threshold, suggesting a role for phosphorylation of CREB in the early maintenance of mechanical hyperalgesia induced by intramuscular acid injection.

The temporal effects of the cAMP pathway activation are seen in other models of neuroplasticity. The early phase of long-term potentiation is dependent on the activation of the cAMP pathway; inhibition of this pathway decreases early long-term potentiation (Blitzer et al., 1995; Otmakhova et al., 2000). In the hippocampus, PKA activity rapidly increases in the initial stages of spatial learning and starts to decrease when protein kinase $\mathrm{C}$ (PKC) activity is maximal at later stages (Vazquez et al., 2000).
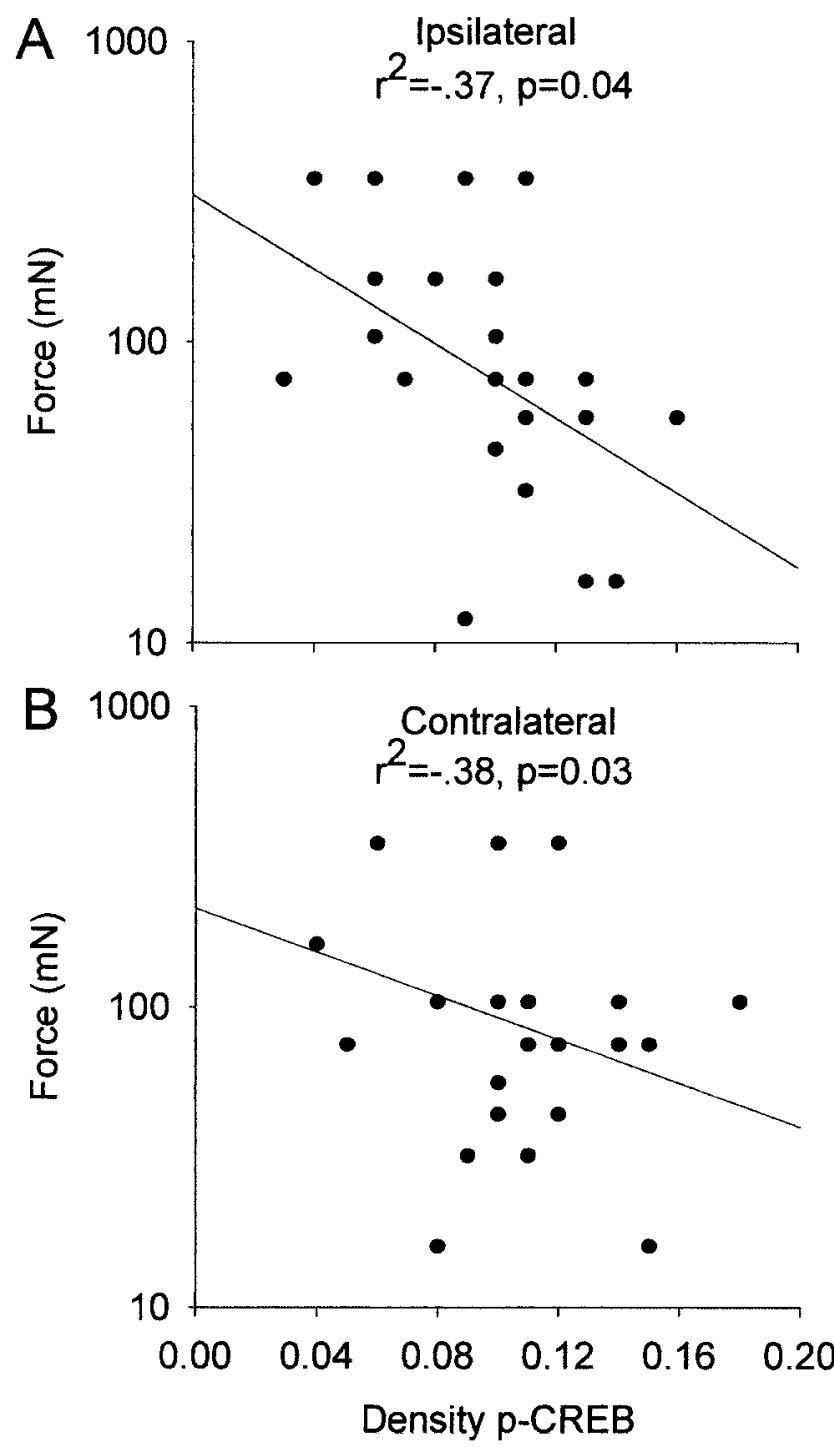

Figure 6. Scatter plots showing the correlation of the mechanical withdrawal threshold ipsilaterally $(A)$ and contralaterally $(B)$ to the density of p-CREB immunoreactivity of the superficial dorsal horn at $24 \mathrm{hr}$. All animals at $24 \mathrm{hr}$ were included in the analysis, and each point represents an individual animal.

PKC activation appears to be critical in the later maintenance phase of long-term potentiation and memory (Sweatt, 1999; Vazquez et al., 2000). Thus, the mechanical hyperalgesia observed in the current study and a previous report (Sluka, 2002) show a pattern similar to that observed in long-term potentiation and memory. On the basis of these data, we hypothesize that PKC plays a role in the later phase. In support of this hypothesis, mice lacking PKC $\gamma$ have no differences in their acute pain responses to heat or mechanical stimuli (Malmberg et al., 1997b). In a more chronic neuropathic pain model, however, both mechanical and heat hyperalgesia were markedly reduced (Malmberg et al., 1997b). Therefore, these results indicate that PKA is involved in the early maintenance of chronic muscle hyperalgesia, but some other molecule, such as PKC, is involved in the later maintenance of hyperalgesia.

The cAMP pathway within the spinal cord plays an integral role in nociceptive processing. Specifically, activation of the cAMP pathway potentiates dorsal horn neurons in vitro (Cerne et al., 1992, 1993), sensitizes spinothalamic tract cells to noxious 
mechanical stimuli in vivo (Lin et al., 2002), and produces mechanical hyperalgesia in vivo (Sluka, 1997, 2002; Dolan and Nolan, 2001). Conversely, spinal blockade of the cAMP pathway reverses mechanical hyperalgesia produced by intradermal, intramuscular, or intra-articular injection of capsaicin (Sluka, 1997, 2002) and reverses capsaicin-induced sensitization of spinothalamic tract cells (Sluka et al., 1997). Thus, activation of the cAMP pathway in the dorsal horn, including spinothalamic tract neurons, could sensitize dorsal horn neurons to noxious mechanical input resulting in mechanical hyperalgesia, as observed after repeated intramuscular acid injection.

\section{Summary}

In summary, the phosphorylation of CREB occurs in a timedependent manner that parallels the cAMP-dependent phase of mechanical hyperalgesia. These increases in $\mathrm{p}$-CREB are reversed by blockade of the cAMP pathway and correlate with the mechanical withdrawal threshold, suggesting that increases in p-CREB may contribute to the mechanical hyperalgesia associated with repeated intramuscular acid injection. Thus, these data provide clinical relevance in that modulation of the cAMP pathway may be beneficial in the early stages of muscle hyperalgesia.

\section{References}

Anderson LE, Seybold VS (2000) Phosphorylated cAMP response element binding protein increases in neurokinin-1 receptor immunoreactive neurons in rat spinal cord in response to formalin-induced nociception. Neurosci Lett 283:29-32.

Bear MF, Connors BW, Paradiso MA (2001) Neuroscience: exploring the brain. In: Molecular mechanisms of learning and memory (Katz S, ed), pp 804-805. Baltimore: Lippincott Williams \& Wilkins.

Bennett RM (1995) Fibromyalgia: the commonest cause of widespread pain. Compr Ther 21:269-275.

Blackstone C, Murphy TH, Moss SJ, Baraban JM, Huganir RL (1995) cAMP and synaptic activity-dependent phosphorylation of AMPA-preferring glutamate receptors. J Neurosci 14:7585-7593.

Blitzer RD, Wong T, Nouranifar R, Iyengar R, Landau EM (1995) Postsynaptic cAMP pathway gates early LTP in hippocampal CA1 region. Neuron 15:1403-1414.

Calejesan AA, Kim SJ, Zhuo M (2000) Descending failitatory modulation of a behavioral nociceptive response by stimulation in the adult rat anterior cingulate cortex. Eur J Pain 4:83-96.

Cerne R, Jaing M, Randic M (1992) Cyclic adenosine 3'5'-monophosphate potentiates excitatory amino acid and synaptic responses of rat spinal dorsal horn neurons. Brain Res 596:111-123.

Cerne R, Rusin KI, Randic M (1993) Enhancement of the N-methyl-Daspartate response in spinal dorsal horn neurons by cAMP dependent protein kinase. Neurosci Lett 161:124-128.

Craig AD, Heppelmann B, Schaible HG (1988) The projection of the medial and posterior articular nerves of the cat's knee to the spinal cord. J Comp Neurol 276:279-288.

Dolan S, Nolan A (2001) Biphasic modulation of nociceptive processing by the cyclic AMP-protein kinase A signaling pathway in sheep spinal cord. Neurosci Lett 309:157-160.

Gonzales GA, Montminy MR (1989) Cyclic AMP stimulates somatostatin gene transcription by phosophorylation of CREB at serine 133. Cell 59: $675-680$.

Gopalkrishnan P, Sluka KA (2001) Effect of varying frequency, intensity and pulse duration of TENS on primary hyperalgesia in inflamed rats. Arch Phys Med Rehabil 81:984-990.

Harris TE, Persaud SJ, Jones PM (1997) Pseudosubstrate inhibition of cyclic AMP-dependent protein kinase in intact pancreatic islets: effects on cyclic AMP-dependent and glucose-dependent insulin secretion. Biochem Biophys Res Commun 232:648-651.

Hell JW, Yokoyama CT, Breeze LJ, Chavkin C, Catterall WA (1995) Phosphorylation of presynaptic and postsynaptic calcium channels by cAMP dependent protein kinase in hippocampal neurons. EMBO J 14:3036-3044.

Hershey AD, Dykema PE, Krause JE (1991) Organization, structure and expression of the gene encoding the rat substance P receptor. J Biol Chem 266:4366-4374.

Hoeger MK, Sluka KA (2001) The role of the cAMP pathway in a chronic muscle pain model in the rat. Soc Neurosci Abstr 27:891.3.

Hoeger MK, Sluka KA (2002) Increased phosphorylation of CREB and reversal by blockade of adenylate cyclase in a chronic muscle pain model in the rat. Paper presented at 10th World Congress on Pain, San Diego, August. Abstract 23-P19.

Ji RR, Rupp F (1997) Phosphorylation of transcription factor CREB in rat spinal cord after formalin-induced hyperalgesia: relationship to c-fos induction. J Neurosci 17:1776-1785.

Ji RR, Brenner GJ, Schmoll R, Baba H, Woolf CJ (2000) Phosphorylation of ERK and CREB in nociceptive neurons after noxious stimulation. In: Proceedings of 9th World Congress on Pain (Devor M, Rowbotham MC, Wiesenfeld-Hallin Z, eds), Vol 16, pp 191-198. Seattle: IASP.

Klein CM, Coggeshall RE, Carlton SM, Westlund KN, Sorkin LS (1990) Changes in calcitonin gene-related peptide immunoreactivity in the rat dorsal horn following electrical stimulation of the sciatic nerve. Neurosci Lett 115:149-154.

Le Guen S, Gwenaelle C, Besson JM (1998) Development of tolerance to the antinociceptive effect of systemic morphine at the lumbar spinal cord level: a c-Fos study in the rat. Brain Res 813:128-138.

Lin Q, Wu J, Willis WD (2002) Effects of protein kinase A activation on the responses of primate spinothalamic tract neurons to mechanical stimuli. J Neurophysiol 88:214-221.

Lonze BE, Ginty DD (2002) Function and regulation of CREB family transcription factors in the nervous system. Neuron 35:605-623.

Ma W, Quirion R (2001) Increased phosphorylation of the cyclic AMP response element-binding protein (CREB) in the superficial dorsal horn neurons following partial sciatic nerve ligation. Pain 93:295-301.

Malmberg AB, Brandon EP, Idzerda RL, Liu H, McKnight GS, Basbaum AI (1997a) Diminished inflammation and nociceptive pain with preservation of neuropathic pain in mice with a targeted mutation of the type I regulatory subunit of cAMP dependent protein kinase. J Neurosci 17:7462-7470.

Malmberg AB, Chen C, Tonegawa S, Basbaum AI (1997b) Preserved acute pain and reduced neuropathic pain in mice lacking PKC gamma. Science 278:279-283.

Martin WJ, Liu H, Wang H, Malmberg AB, Basbaum AI (1999) Inflammation-induced up-regulation of protein kinase $\mathrm{C} \gamma$ immunoreactivity in rat spinal cord correlates with enhanced nociceptive processing. Neuroscience 88:1267-1274.

Mense S (1993) Nociception from skeletal muscle in relation to clinical muscle pain. Pain 54:241-289.

Mense S, Prabhakar NR (1986) Spinal termination of nociceptive afferent fibres from deep tissues in the cat. Neurosci Lett 66:169-174.

Messersmith DJ, Kim DJ, Iadarola MJ (1998) Transcription factor regulation of prodynorphin gene expression following rat hindpaw inflammation. Mol Brain Res 53:259-269.

Miletic G, Pankratz MT, Miletic V (2002) Increases in the phosphorylation of cyclic AMP response element binding protein (CREB) and decreases in the content of calcineurin accompany thermal hyperalgesia following chronic constriction injury in rats. Pain 99:493-500.

Nibuya M, Nestler EJ, Duman RS (1996) Chronic antidepressant administration increases the expression of cAMP response element-binding protein (CREB) in rat hippocampus. J Neurosci 16:2365-2372.

Otmakhova NA, Otmakhov N, Mortenson LH, Lisman JE (2000) Inhibition of the cAMP pathway decrease early long-term potentiation at CA1 hippocampal synapses. J Neurosci 20:4446-4451.

Pogatski EM, Zahn PK, Brennan TJ (2000) Lumbar catheterization of the subarachanoid space with a 32-gauge polyurethane catheter in the rat. Eur J Pain 4:111-113.

Porreca F, Ossipov MH, Gebhart GF (2002) Chronic pain and medullary descending facilitation. Trends Neurosci 25:319-325.

Sakura S, Hashimoto K, Bollen AW, Ciriales R, Drasner K (1996) Intrathecal catheterization in the rat. Improved technique for morphologic analysis of drug-induced injury. Anesthesiology 85:1184-1189.

Sassone-Corsi P, Visvader J, Ferland L, Mellon PL, Verma IM (1988) Induction of proto-oncogene fos transcription through the adenylate cyclase pathway: characterization of a cAMP responsive element. Genes Dev 2:1529-1538. 
Schaible HG, Grubb BD (1993) Afferent and spinal mechanisms of joint pain. Pain 55:5-54

Shaywitz AJ, Greenberg ME (1999) CREB: a stimulus-induced transcription factor activated by a diverse array of extracellular signals. Annu Rev Biochem 68:821-861.

Skyba DA, King EW, Sluka KA (2002) Effects of NMDA and non-NMDA ionotropic glutamate receptor antagonists on the development and maintenance of hyperalgesia induced by repeated intramuscular injection of acidic saline. Pain 98:69-78.

Sluka KA (1997) Activation of the cAMP transduction cascade contributes to the mechanical hyperalgesia and allodynia induced by intradermal injection of capsaicin. Br J Pharmacol 122:1165-1173.

Sluka KA (2002) Stimulation of deep somatic tissue with capsaicin produces long-lasting mechanical allodynia and heat hypoalgesia that depend on early activation of the cAMP pathway. J Neurosci 22:5687-5693.

Sluka KA, Westlund KN (1993) Behavioral and immunohistochemical changes in an experimental arthritis model in rats. Pain 55:367-377.

Sluka KA, Willis WD (1997) The effects of G-protein and protein kinase inhibitors on the behavioral responses of rats to intradermal injection of capsaicin. Pain 71:165-178.

Sluka KA, Dougherty PM, Sorkin LS, Willis WD, Westlund KN (1992) Neural changes in acute arthritis in monkeys. III. Changes in substance P, calcitonin gene-related peptide and glutamate in the dorsal horn in the spinal cord. Brain Res Rev 17:29-38.

Sluka KA, Kalra A, Moore SA (2001) Unilateral intramuscular injections of acidic saline produce a bilateral, long-lasting hyperalgesia. Muscle Nerve 24:37-46.

Storkson RV, Kjorsvik A, Tjolsen A, Hole K (1996) Lumbar catheterization of the spinal subarachnoid space in the rat. J Neurosci Methods 65:167-172.

Sweatt JD (1999) Toward a molecular explanation for long-term potentiation. Learn Mem 6:399-416.

Urban MO, Zahn PK, Gebhart GF (1999) Descending facilitatory influences from the rostral medial medulla mediate secondary, but not primary, hyperalgesia in the rat. Neuroscience 90:349-352.

Vazquez SI, Vazquez A, Pena de Ortiz S (2000) Different hippocampal activity profiles for PKA and PKC in spatial discrimination learning. Behav Neurosci 114:1109-1118.

Walsh DA, Glass DB (1991) Utilization of the inhibitor protein of adenosine cyclic monophosphate-dependent protein kinase, and peptides derived from it, as tools to study adenosine cyclic monophosphate-mediated cellular processes. Methods Enzymol 201:304-316.

Wei F, Qiu CS, Kim SJ, Muglia L, Maas JW, Pineda VV, Xu HM, Chen ZF, Storm DR, Muglia LJ, Zhuo M (2002) Genetic elimination of behavioral sensitization in mice lacking calmodulin-stimulated adenylyl cyclases. Neuron 36:713-726.

White DM, Helme RD (1985) Release of substance P from peripheral nerve terminals following electrical stimulation of the sciatic nerve. Brain Res 336:27-31.

Willis WD, Coggeshall RE (1991) Sensory mechanisms of the spinal cord, Ed 2. New York: Plenum.

Xia Z, Storm DR (1997) Calmodulin-regulated adenylyl cyclases and neuromodulation. Curr Opin Neurobiol 7:391-396.

Zou X, Lin Q, Willis WD (2000) Enhanced phosphorylation of NMDA receptor 1 subunits in spinal cord dorsal horn and spinothalamic tract neurons after intradermal injection of capsaicin in rats. J Neurosci 20:6989-6997. 